\title{
İki Intramusküler Lipom Olgusu: Radyolojik Bulgular
}

\section{Two Intramuscular Lipoma Case Reports: Radiological Findings}

\author{
Ayşe Umul ${ }^{1}$, Ömer Yılmaz ${ }^{1}$ \\ ${ }^{1}$ Süleyman Demirel Üniversitesi Tıp Fakültesi, Radyoloji Anabilim Dalı
}

\section{ÖZET}

Lipom, sık görülen mezenşimal kökenli bir yumuşak doku tümörüdür. Matür yağı doku içerirler. Genellikle subkutan dokuya yerleşirler. Kas içerisine yerleşimleri nadir görülür ve bu durumda intramusküler lipom olarak adlandırılırlar. Ultrasonografi, seçilecek ilk tanı yöntemidir. Ancak, kesitsel görüntüleme yöntemleri tanıda daha faydalıdır. Manyetik rezonans görüntülemede (MRG), sinyal özellikleri ve yağ baskılama tekniklerinin katkısıyla tanıya kolaylıkla ulaşılır. Ayrıca lezyonun komşu anatomik yapılarla ilişkisi de MRG ile daha iyi değerlendirilebilir. Burada, iki farklı yerleşimli intramusküler lipom olgusu anlatılacak ve görüntüleme bulguları gözden geçirilecektir.

Anahtar kelimeler: yağlı, intramusküler, lipom, tanı

\section{ABSTRACT}

Lipomas are common soft tissue tumors of mesenchymal origin. They contain mature adipose tissue. They are usually located in the subcutaneous tissue. They rarely ocur within the muscle and then are called intramuscular lipomas. Ultrasonography is the first diagnostic method to be selected. However, cross-sectional imaging methods are more useful in the diagnosis. On Magnetic resonance imaging (MRI), with the help of signal characteristics and fat suppression techniques, diagnosis is easily achieved. In addition, the relationship of lesion with the adjacent anatomical structures can be assessed better with MRI. Here, will be explained two different intramuscular lipoma cases and imaging findings will be reviewed.

Key words: fatty, intramuscular, lipom, diagnosis
CorrespondingAuthor: Ayşe Umul

Address: Süleyman Demirel Üniversitesi Tıp Fakültesi,

Radyoloji Anabilim

Isparta, Türkiye

E-mail: ayseumul@gmail.com
BaşvuruTarihi/Received:28-10-2015

Kabul Tarihi/Accepted: 26-11-2015

Tel number: +905454545380 


\section{GiRiş:}

Lipom, en sık görülen yumuşak doku tümörü olup mezenşimal kökenlidir(1). Tipik olarak subkutan yerleşimli olup matür yağlı doku içerirler. Tamamen benign lezyonlardır. Yüzeyel ve derin yerleşimli olmak üzere iki gruba ayrılırlar. Derin erleşimli grup içerisindeki lipomlar kas içerisine yerleşirse intramusküler lipom olarak adlandırılır(1). Amacımız, iki ayrı olgu eşliğinde intramusküler lipomları radyolojik bulgularını vurgulayarak anlatmaktır.
Olgu 1: Kırk beş yaşında, guatr operasyonu geçiren ve tiroid bezi bulunmayan bayan hasta, rutin kontroller için hastanemize başvurdu. Beş yıl önce multinodüler guatr teşhisiyle total tiroidektomi olmuş. Klinik şikayeti olmayan olgunun boyun fizik muayenesi normaldi. Yapılan boyun ultrason incelemesinde (Toshiba Aplio 500, Japan 2013); tiroid bezi saptanmadı. Sağda strep kaslarda sola kıyasla boyut artışı ve kas içerisinde $7 \times 4$ $\mathrm{mm}$ boyutlu iyi sınırlı düzgün konturlu hiperekojen solid lezyon izlendi (Resim 1).
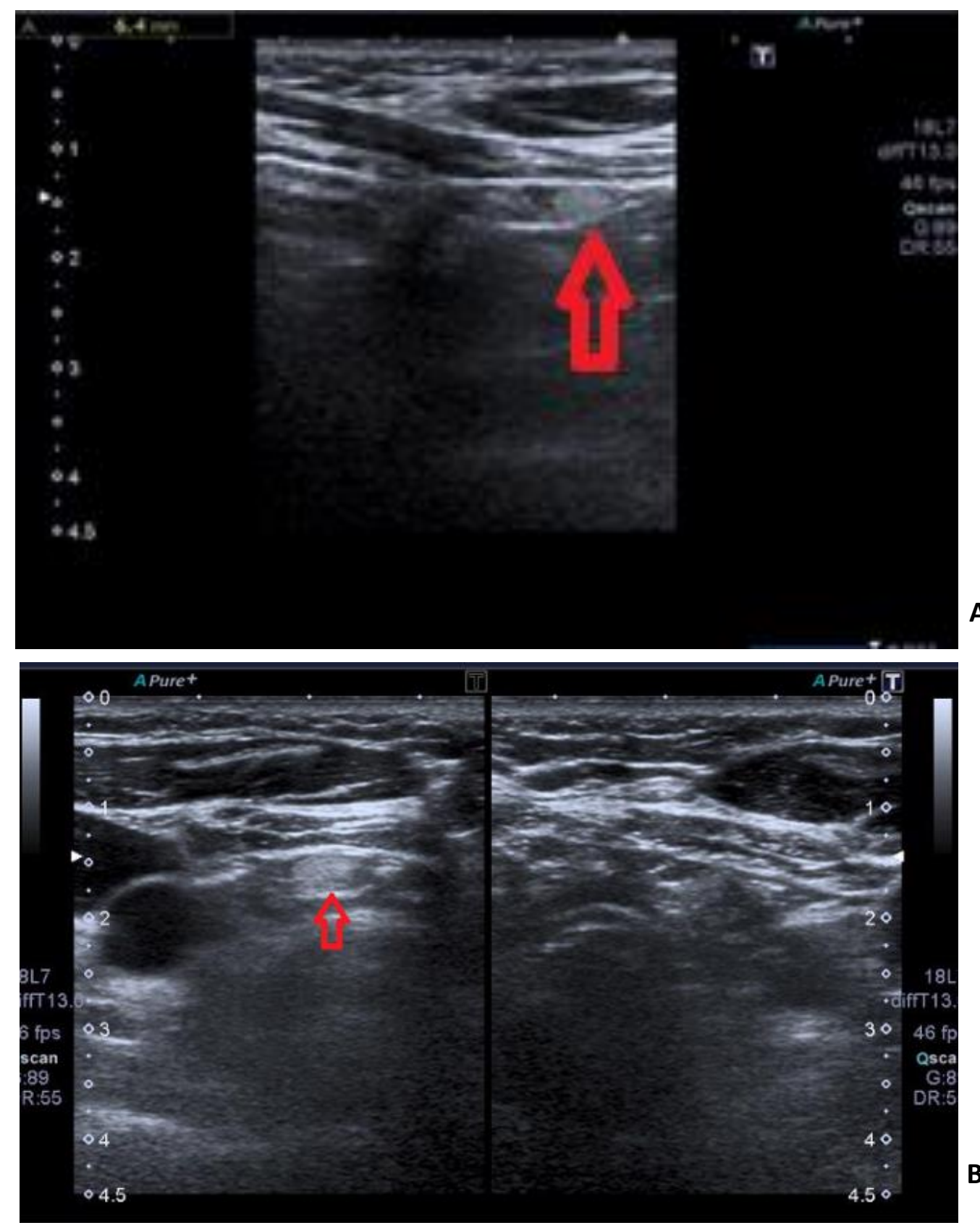

Resim 1. Boyuna yönelik yapılan USG'de transvers (A) ve longitudinal (B) görüntülerde sağ strep kası içerisinde iyi sınırlı, homojen iç yapıda hiperekojen solid lezyon izleniyor (ok). Normal olan sol strep kas ok başı ile gösteriliyor. 
Tipik sonografik özelliği ile ön tanıda lipom düşünüldü. Asemptomatik olan olguya cerrahi uygulanmadı ve takip önerildi.

Olgu 2: Kırk üç yaşında bayan hasta sağ uylukta ele gelen şişlik nedeniyle hastanemize başvurdu. Lokal fizik muayenede cildin altında yaklaşık $11 \times 8 \mathrm{~cm}$ boyutlu kitle palpe edildi. MRG'de (Siemens Magnetom Avanto MR Syngo 1.5 T; Siemens Medical Solutions, Erlangen,gelen şişlik nedeniyle hastanemize başvurdu. Lokal fizik muayenede cildin altında yaklaşık $11 \times 8 \mathrm{~cm}$ boyutlu kitle palpe edildi. MRG'de (Siemens
Magnetom Avanto MR Syngo 1.5 T; Siemens Medical Solutions, Erlangen, Germany) sağ rektus femoris kası içerisinde yaklaşık $11 \times 8 \times 4$ $\mathrm{cm}$ boyutlarında $T 1$ ve $T 2$ ağırlıklı görüntülerde hiperintens karakterde ve yağ baskılı imajlarda, sinyali baskılanarak hipointens hale gelen lezyon izlendi. iV kontrast madde verildikten sonra alınan yağ baskılı T1 ağırlıklı görüntülerde kontrast tutuluşu gözlenmedi (Resim 2). Karakteristik görüntüleme bulguları ile intramusküler lipom düşünüldü. Cerrahi istemeyen olguya kontrol ve takip önerildi.
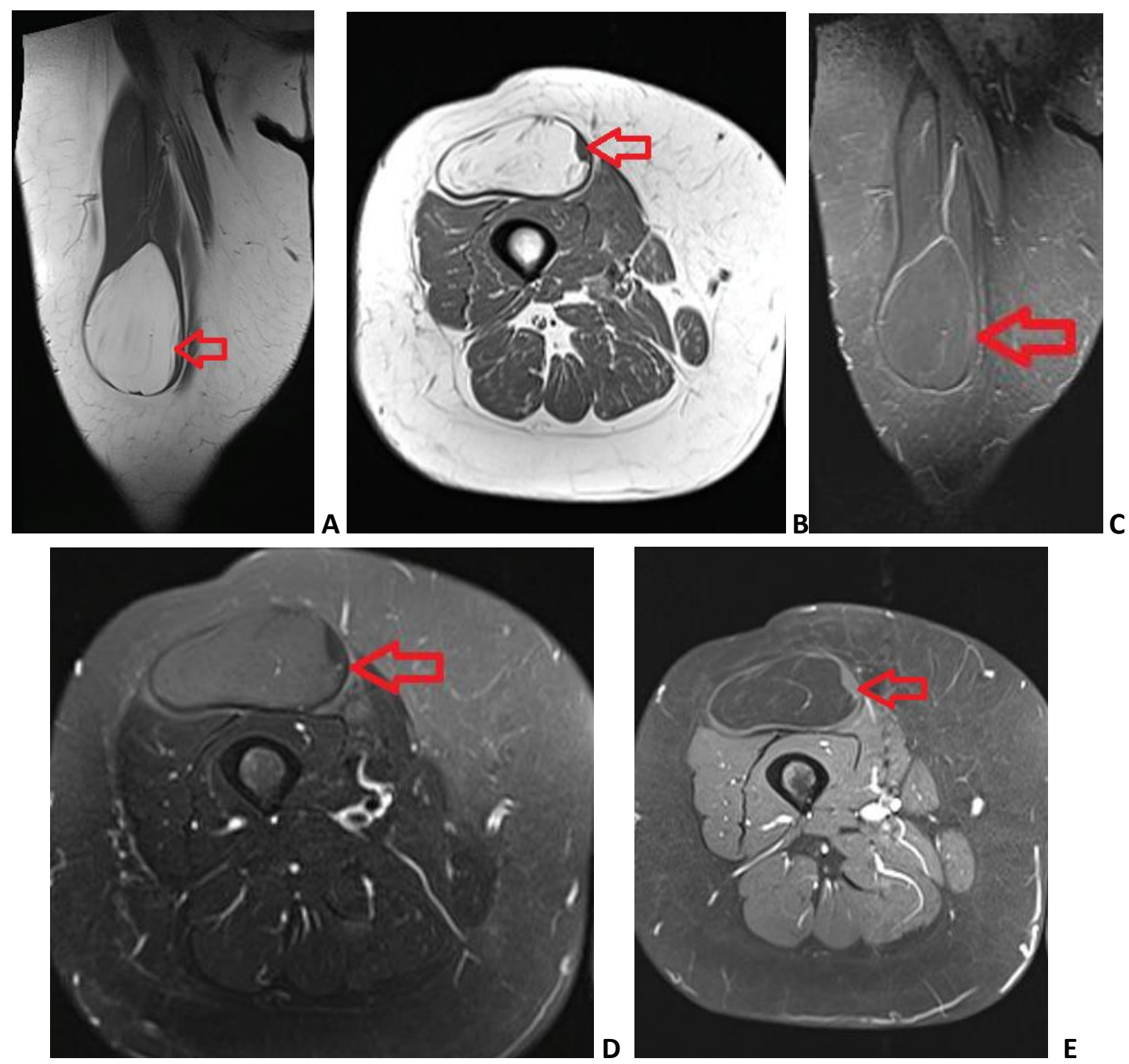

E

Resim 2. Sağ uylukta anteriorda rektus femoris kası içerisinde T1 ağırlıklı görüntülerde hiperintens, yağ baskılı serilerde baskılanan ve kontrastlı görüntülerde hafif cidarsal kontrastlanma dışında kontrast tutuluşu göstermeyen kitle lezyonu izleniyor (A. Koronal ve B. Aksiyel T1 ağırlıklı görüntü C. Koronal ve D. Aksiyel yağ baskılı T2 ağırlıklı görüntü $E$. Kontrast madde sonrası yağ baskılı T1 ağırıklı görüntü) 


\section{Tartışma:}

Intramusküler lipomlar tüm lipomların yaklaşık \% 1 'ini oluşturur $(2,3)$. Genellikle tek bir kas içerisinde lokalize olur, birden fazla kas içerisine yerleşimi çok nadir görülür $(4,5)$. Tüm yaş gruplarında görülebilir fakat büyük çoğunluğu 40 ile 70 yaş arasında görülür $(2,6)$. Cinsiyet farkı bulunmaz (1).

Genellikle gövde ve ekstremitelerin büyük kaslarına yerleştiği düşünülse de vücuttaki tüm kaslarda yerleşebilir (7-11). Baş ve boyun bölgesinde dil, çene yada göz kaslarında görülebilir (6,12-17). İnfrahyoid kaslar olan strep kaslarda yerleşimi çok nadirdir.

Etyoloji ve patogenezi net olarak bilinmemektedir. Ancak intramusküler lipom multipotent mezenşimal hücrelerden köken alan gerçek bir neoplazidir. Ayrıca, travma, kronik irritasyon, obezite , gelişmsel anomaliler, endokrin ve genetik faktörler de intramusküler lipomun gelişiminde rol oynarlar $(18,19)$. Klinik olarak yavaş büyüyen asemptomatik şişlik olarak prezente olurlar. Ağrı genellikle bulunmaz ve çok büyük lipomlarda çevre yumuşak dokuların kompresyonu nedeniyle gelişir $(10,19)$.

Fizik muayenede palpable kitle yada yumuşak doku şişliği saptanabilir. illk vakada, yerleşim yeri ve boyutu nedeniyle palpe edilmiyordu.

Görüntüleme; tanıyı koymada , boyutu ve lokalizasyonu tanımlamada, komşu anatomik yapılarla ilişkisini belirlemede ve cerrahi planlamada önemlidir.

Ultrasonografi, lipomatöz tümörlerde ilk seçilecek tanı yöntemidir (20). Çoğu olguda lipom komşu kas dokuya göre hiperekojen izlenir fakat izoekoik yada hipoekoik de olabilir. Akustik güçlenme görülebilir. Genellikle internal vaskülarite bulunmaz.

USG, intramusküler lipomda kullanılan ilk modalite olmasına ve kitlenin yağlı içeriğini göstermesine rağmen, kesitsel görüntüleme yöntemleri, tanının daha kolay konmasını sağlar. Ayrıca USG'de komşu anatomik yapılarla ilişkisini değerlendirmek zor olabilir.

Bilgisayarlı tomografide, kas içerisinde yerleşen hipodens kitle şeklinde görülürler ve lezyon içerisinde yağ ile uyumlu negatif Hounsfield değerleri (HU) saptanır (21). Kitlenin şekli değişkendir ancak genellikle oval yada fusiform şekillidir.

MRG, yağ içeren tümörleri, diğer yumuşak doku tümörlerinden ayırmada ve lipomatöz kitleleri de kategorize etmede mükemmel bir tekniktir. MRG bulguları değişkendir. Lezyonun şekli yuvarlak, oval yada irregüler olabilir (22). Yağlı doku, T1 ve T2 ağırlıklı görüntülerde hiperintens izlenir ve yağ baskılı kesitlerde normal yağ ile benzer şekilde sinyal kaybı izlenir. Subkutan yağ dokuya benzer şekilde homojen olabilir yada heterojen iç yapıda da görülebilirler. Kontrastlı incelemelerde genellikle kontrast tutulumu gözlenmez ancak bazı olgularda minimal kontrastlanma görülebilir.

Ayırıcı tanıda öncelikle düşük dereceli liposarkom akla gelmelidir. Malignite riski; artmış yaş, $10 \mathrm{~cm}$.nin üzerinde lezyon boyutu, $2 \mathrm{~mm}$.den daha kalın septasyon varlığı, nodüler yada globüler nonadipoz kitle benzeri komponent bulunması ve yağ içeriğinin azalıp heterojen görünüm ile ilişkidir(23). Bizim vakalarımızdaki lezyonların homojen olması, kalın septasyon ya da nonadipoz solid komponentin bulunmaması nedeniyle liposarkomu öncelikli olarak düşünmedik.

Tedavi, tümörün lokalizasyonuna, boyutuna ve klinik bulgularına göre değişkenlik gösterir. Semptomatik hastada konservatif tedavi yetersiz kalabilir ve uygulanacak tedavi cerrahi eksizyondur. Geniş eksizyon, rekürrensi engellemede faydalıdır (24).

Rekürrens nadir görülür ve genellikle lipomun tam çıkarılamamasından kaynaklanır $(19,25)$. 
Sonuç olarak; intramusküler lipom mezenşimal kökenli, matür yağlı doku içeren ve nadir görülen bir benign tümördür. Ultrasonografi, seçilecek ilk tanı yöntemidir.
Kesitsel görüntüleme yöntemleri tanıda daha faydalıdır. Manyetik rezonans görüntüleme, tipik sinyal özellikleri ve yağ baskılama tekniklerinin yardımıyla tanı koydurucudur.

\section{KAYNAKLAR}

1. McTighe S, Chernev I. Intramuscular lipoma: a review of the literature. Orthopedic Reviews 2014; 6:5618.

2. Fletcher $C D$, Martin-Bates E. Intramuscular and intermuscular lipoma: neglected diagnoses. Histopathology 1988;12:275-87.

3. Lee JH, Do HD, Lee JC. Well-circumscribed type of intramuscular lipoma in the chest wall. J Cardiothorac Surg 2013;8:181.

4. Morris AD, Jane MJ, Ritchie D, Helliwell T. Diffuse intramuscular lipomatosis of a lower limb. Sarcoma 1998;2:53-6.

5. Matsumoto K, Hukuda $S$, Ishizawa $M$, et al. Liposarcoma associated with multiple intramuscular lipomas. A case report. Clin Orthop Relat Res 2000;373:202-7.

6. Dutton J, Wright J. Intramuscular lipoma of the superior oblique muscle. Orbit 2006;25:227-33.

7. Balabram D, Cabral CCdSR, Filho OdPR, Barros CPd. Intramuscular lipoma of the subscapularis muscle. Sao Paulo Med J 2014;132:65-7.

8. Ramos Pascua L, Alonso León A, Santos Sánchez JA, Ferrández Portal L.Intramuscular lipoma of the deltoid mimicking a sarcoma. A case report. Chir Organi Mov 2001;86:153-7.

9. Gopal U, Patel MH, Wadhwa MK. Intramuscular lipoma of the pectoralis major muscle. J Postgraduate Med 2002;48:330.

10. Gutknecht DR. Painful intramuscular lipoma of the thigh. South Med J 2004;97:1121-2.

11. Harrington AC, Adnot J, Chesser RS. Infiltrating lipomas of the upper extremities. J Dermatol Surg Oncol 1990;16:834-7.

12. Collela G, Lanza A, Rossiello L, Rossiello R. Infiltrating lipoma of the tongue. Oral Oncology Extra 2004;40:33-5.

13. Ban M, Kitajima Y. Intramuscular lipoma within the temporal muscle. Int J Dermatol 2002; 41:689 -90 .
14. Charles NC, Palu RN. Intramuscular lipoma of the eyelid. Ophthalmic Surg Lasers 2000;31:340-1.

15. Bandeca MC, De Padua JM, Nadalin MR, et al. Oral soft tissue lipomas: a case series. J Canad Dental Assoc 2007;73:431-4.

16. Sohn W, Kim JH, Jung SN, et al. Intramuscular lipoma of the sternocleidomastoid muscle. J Craniofacial Surg 2010;21:1976-8.

17. Piattelli A, Fioroni M, Rubini C. Intramuscular lipoma of the cheek: a case report. J Oral Maxillofac Surg 2000;58:817- 9.

18. Copcu E. Can intramuscular lipoma have a posttraumatic origin? Br J Dermatol 2003;149:1084-5.

19. Ramos-Pascua LR, Guerra-Álvarez OA, SánchezHerráez S, et al. Intramuscular lipomas: Large and deep benign lumps not to be underestimated. Review of a series of 51 cases. Rev Esp Cir Ortop Traumatol 2013;57:391-7.

20. Inampudi $P$, Jacobson JA, Fessell DP, et al. Soft-tissue lipomas: accuracy of sonography in diagnosis with pathologic correlation. Radiology 2004; 233:763-7.

21. Pant R, Poh ACC, Hwang SG. An unusual case of an intramuscular breast mass. Ann Acad Med Singapore 2005;34:275-6.

22. Matsumoto $K$, Hukuda $S$, Ishizawa $M$, Chano $T$, Okabe $\mathrm{H}$. MRI findings in intramuscular lipomas. Skeletal Radiol 1999;28:145-52.

23. Subhawong TK, Fishman EK, Swart JE, Carrino JA, Attar S, Fayad LM. Soft-Tissue Masses and Masslike Conditions: What Does CT Add to Diagnosis and Management? AJR 2010; 194:1559-1567.

24. Nishida J, Morita $T$, Ogose A, et al. Imaging characteristics of deep-seated lipomatous tumors: intramuscular lipoma, intermuscular lipoma, and lipoma-like liposarcoma. J Orthop Sci 2007;12:533-41.

25. Su CH, Hung JK, Chang IL. Surgical treatment of intramuscular, infiltrating lipoma. Int Surg 2011;96: 56-9. 